\title{
BMJ Suboptimal prescribing of proton-pump Open inhibitors in low-dose aspirin users: a cohort study in primary care
}

\author{
Hilda J I de Jong, ${ }^{1}$ Joke C Korevaar, ${ }^{1}$ Liset van Dijk, ${ }^{1}$ Eef Voogd, ${ }^{1}$ \\ Christel E van Dijk, ${ }^{1}$ Martijn G $\mathrm{H}$ van Oijen ${ }^{2,3}$
}

To cite: de Jong HJl, Korevaar JC, van Dijk L, et al. Suboptimal prescribing of proton-pump inhibitors in low-dose aspirin users: a cohort study in primary care. BMJ Open 2013;3: e003044. doi:10.1136/ bmjopen-2013-003044

- Prepublication history and additional material for this paper is available online. To view these files please visit the journal online (http://dx.doi.org/10.1136/ bmjopen-2013-003044).

Received 12 April 2013 Revised 11 June 2013 Accepted 25 June 2013
${ }^{1}$ NIVEL, Netherlands Institute for Health Services Research, Utrecht, The Netherlands ${ }^{2}$ Division of Digestive Diseases, David Geffen School of Medicine, UCLA, Los Angeles, California, USA ${ }^{3}$ Department of Medicine, UCLA/VA Center for Outcomes Research and Education (CORE), LoS Angeles, California, USA

Correspondence to Joke C Korevaar; j.korevaar@nivel.nl

\section{ABSTRACT}

Objective: Determine the adherence to recommendations of concomitant proton-pump inhibitor (PPI) treatment in regular low-dose of aspirin (LDASA) users, taking factors associated with the probability of receiving a PPI into account.

Design: Cohort study.

Setting: Data were obtained from 120 Dutch primary care centres participating in the Netherlands Information Network of Primary Care (LINH).

Participants: Patients 18 years and older who were regularly prescribed LDASA $(30-325 \mathrm{mg})$ in 2008-2010 were included.

Main outcome measures: Regular medication use was defined as receiving each consecutive prescription within 6 months after the previous one. Based on national guidelines, we categorised LDASA users into low and high gastrointestinal (Gl) risk. A multilevel multivariable logistic regression analysis was applied to identify patient characteristics that influenced on the probability of regular PPI prescriptions.

Results: We identified 12343 patients who started LDASA treatment, of whom $3213(26 \%)$ were at increased risk of $\mathrm{GI}$ complications. In this group, concomitant regular use of PPI was $46 \%, 36 \%$ did not receive PPI prescriptions and $18 \%$ obtained prescriptions irregularly $(p<0.0001)$. The chance to obtain regularly PPI prescriptions versus no PPI was significantly influenced by, among others, previous $\mathrm{Gl}$ complications (OR 13.9 (95\% Cl 11.8 to 16.4)), use of non-steroidal anti-inflammatory drugs (OR 5.2 (4.3 to 6.3)), glucocorticosteroids (6.1 (4.6 to 8.0)), selective serotonin reuptake inhibitors (9.1 (6.7 to 12.2)), drugs for functional GI disorders (2.4 (1.9 to 3.0)) and increased age.

Conclusions: Primary care physicians do not fully adhere to the current recommendations to prescribe PPIs regularly to LDASA users with an increased GI risk. More than $50 \%$ of the patients with an increased GI risk are not treated sufficiently with a concomitant $\mathrm{PPI}$, increasing the risk of $\mathrm{GI}$ side effects. This finding underlines the necessity to consider merging recommendations into one common, standard and frequently used recommendation by primary care physicians.

\section{ARTICLE SUMMARY}

Article focus

- Low-dose of aspirin (LDASA) use is associated with a wide variety of gastrointestinal (Gl) side effects.

- Concomitant use of proton-pump inhibitor (PPIs) for patients who are at increased risk for Gl complications is advised.

- Adherence and persistence of PPI use in primary care of patients using LDASA frequently is still indefinite.

\section{Key messages}

- Primary care physicians do not fully adhere to the current recommendations to prescribe PPIs regularly to LDASA users with an increased GI risk.

- Concomitant regular use of PPI with LDASA in patients with an increased GI risk was $46 \%$ in primary care.

- Thirty-six per cent of the LDASA users with an increased GI risk and treated in primary care, obtained no PPI prescriptions, and 18\% obtained prescriptions irregular.

Strengths and limitations of this study

- Large representative sample of patients monitored in daily practice in primary care.

- No information was available why patients with an increased GI risk did not obtain PPI prescriptions, or why they became an irregular PPI user.

\section{INTRODUCTION}

Worldwide, the number of deaths from cardiovascular disease was estimated at 17.3 million in 2008, and it is expected to increase to approximately 23.6 million by $2030{ }^{1}$ Treatment with low-dose of aspirin (LDASA) is recommended for the prevention of cardiovascular events in patients with a history of myocardial infarction, stroke, transient ischaemic attack or (in) stable angina. ${ }^{2-4}$ While LDASA use is associated with a decreased risk of cardiovascular events, ${ }^{5}$ its use is also associated with a wide variety of gastrointestinal 
(GI) side effects, such as dyspepsia, peptic ulcers and upper and lower GI bleedings. ${ }^{6} 7$

GI complications associated with LDASA use are more frequently present in patients who are older than 70 years, have a history of peptic ulcer, have had an infection with Helicobacter pylori and/or used concomitant drug therapies with non-steroidal anti-inflammatory drugs (NSAIDs), including cyclooxygenase-2 (COX-2) inhibitors, other antiplatelet agents or anticoagulants, glucocorticosteroids and/or selective serotonin reuptake inhibitors (SSRIs). ${ }^{6}$ Concomitant proton-pump inhibitor (PPI) therapy is associated with a reduction of the risk of GI complications. ${ }^{8-11}$

Therefore, concomitant use of PPIs for patients who use regular LDASA and are at increased risk for GI complications has been described in guidelines from medical societies and scientific associations from both the USA and Europe. ${ }^{12}{ }^{13}$ In the Netherlands-the setting of our study-an expert group with a focus on optimising extramural medication safety published specific recommendations for adequate GI protection, that is, prescribing PPIs in regular LDASA users with an increased risk of GI complications in 2008, which was finalised in 2009. ${ }^{14}$ These recommendations are in line with the USA, National Institute for Health and Clinical Excellence (NICE) and European Society of Cardiology (ESC) guidelines, ${ }^{12} 1315$ and describe that PPIs are the preferred agents for the therapy and prophylaxis of aspirin-associated GI injury. ${ }^{12}$ Risk reduction due to PPI treatment observed in case-control and cohort studies ranged in most cases from $40 \%$ to $80 \% .{ }^{16}$

Several observational studies described the use of concomitant PPI in patients receiving NSAID including aspirin, and showed that $67-90 \%$ of the users with at least one risk factor did not receive gastroprotective therapy as recommended. ${ }^{17-19}$ Two studies focused on LDASA patients; in one study the definition of increased GI risk was limited, namely a positive $H$ pylori status, the other study had a small sample size of LDASA patients. $^{20} 21$ Although evidence regarding the adherence to concomitant PPI use in patients with an increased risk for GI complications is increasing, the adherence and persistence of PPI use is still indefinite.

The objective of this study is to determine the adherence to recommendations of concomitant PPI treatment in regular LDASA users, taking factors associated with the probability of receiving a PPI into account.

\section{METHODS}

Data were obtained from the Netherlands Information Network of Primary Care Physicians (LINH), a database derived from primary care centres that record data on morbidity, and drug prescriptions on continuous basis in electronic medical records (EMR). The LINH network consists of a dynamic cohort of 700000 patients who are registered at 120 centres. $^{22}$ The network is a representative sample of the Dutch population, it started in 2001 and registration is still on-going. ${ }^{22}$ In the Netherlands, all citizens are registered with a primary care physician who act as a gatekeeper for access to specialised care. ${ }^{23}$

Prescription data were classified according to the Anatomical Therapeutic and Chemical (ATC) classification, ${ }^{24}$ and morbidity was coded by using the International Classification of Primary Care (ICPC) scheme. ${ }^{25}$ The privacy regulation of LINH was approved by the Dutch Data Protection Authority. According to Dutch legislation, neither obtaining informed consent nor approval by a medical ethics committee is obligatory for database studies.

In this longitudinal, observational study, all patients aged 18 years and older who started with regular use of LDASA (30-325 mg) treatment between 1 January 2008 and 31 December 2010 were included under the condition that their history was available at least 1 year before the date of the first prescription of LDASA. This time period was chosen to confirm that no LDASA prescriptions were given in the year prior to inclusion. Regular use of LDASA was defined as receiving each consecutive prescription within 6 months after the previous one. A gap of maximal 6 months was chosen because in daily practice patients rarely collect a subsequent prescription exactly on the day their supply of their previous prescription has ended, normally 90 days, but rather earlier (overlap of two prescriptions) or later (gap between two prescriptions). In order not to bias our results towards irregular user categorisation, we used a maximum period of 6 months. Irregular LDASA users, according to our definition, were excluded from the analyses as well as users with just one LDASA prescription. Aspirin therapy was identified by a prescription of acetylsalicylic acid (ATC-codes B01AC06, N02BA01 and N02BA51), carbasalate calcium (B01AC08, N02BA15 and N02BA65) or acetylsalicylic acid in combination with other drugs (B01AC30).

Based upon the HARM-WRESTLING recommendations, ${ }^{14}$ we categorised new LDASA users into low or increased risk of GI complications. Patients with an increased risk of GI complications were identified by the following selection rules applied in consecutive order: (1) 80 years or older; (2) 70 years or older with simultaneous use of NSAIDs, oral anticoagulants, platelet aggregation inhibitors, glucocorticosteroids, SSRIs and/or spironolacton or (3) 60 years or older with a history of a peptic ulcer.

PPI treatment was identified by ATC-code A02BC. All patients were divided into three categories: no user, irregular or regular user of PPIs. Patients who never received a prescription of PPI during the follow-up period were defined as no PPI users. In line with our definition of a regular LDASA user, patients were defined as regular PPI users if they received each consecutive prescription within 6 months after their previous one. All others were considered as irregular users.

We considered patients to be previous starters of PPIs when they received a prescription of PPI in the year 
prior to the first prescription of LDASA. Patients who started the use of PPIs within a week after the first prescription of LDASA were considered as simultaneous starters of PPIs. Patients who received a prescription of PPI more than a week after the first prescription of LDASA were subsequent starters of PPIs.

Relevant comorbidity was determined in the year before and after the date of the first prescription of LDASA. Cardiovascular and cerebrovascular diseases were identified by ICPC-codes K71, K73-K84, K89-K96 and K99. Hypertension was considered present when the patient had a medical record of ICPC-codes K86 or K87. Patients were classified as diabetic if a diagnosis code for diabetes (T90) was identified, or when they received antidiabetic therapy (ATC-codes A10A and A10B). Patients who had a diagnosis of lipid disorder (T93) or when they received lipid modifying agents (C10) were considered as hypercholesterolaemic. GI complications, including peptic ulcers, were identified by D02, D03, D09, D10, D14, D16, D85-87 and D90 (see online supplementary appendix I). To classify patients as having an increased GI risk based on HARM-WRESTLING recommendation, we determined prescriptions for NSAIDs (M01), including Cox-2 inhibitors, oral anticoagulants and platelet aggregation inhibitors (B01AA and B01AC), glucocorticosteroids (H02AB and H02) and SSRIs (N06AB). ${ }^{14}$ In addition, we identified all prescriptions for cardiovascular system (C01-C10), acidrelated disorders (A02 (PPIs excluded)) and functional GI disorders (A03) in the year before and after the date of the first LDASA prescription. Finally, cardiac therapy was defined as a prescription of an ATC-code C01 in the year before or after the first LDASA prescription.

\section{Statistical analysis}

Differences between groups were tested with a $\chi^{2}$ test. To identify the relative influence of patient characteristics on the probability to obtain regular PPI prescriptions, multilevel multivariable logistic regression analyses (backward elimination method) was conducted. The models were estimated taking the clustering of patients (level 1) within primary care centres (level 2) into account. The probability of receiving a PPI was determined by comparing no PPI users with regular PPI users. This analysis was performed without the irregular users to rule out the effect of these users. In addition, separate analyses were performed for increased GI risk patients. All data were analysed using the statistical program SAS V.9.2 (SAS Institute, Cary, North Carolina, USA) and 'Multilevel models for windows' (MLwin 2.02). Adjustment for multiple testing was performed by using a False Discovery Rate correction.

Choices of our definition of subsequent and simultaneous start of PPIs, and our period of describing patients' characteristics were based on assumptions, and therefore we tested the robustness of our findings by performing sensitivity analyses. We made the definition of simultaneous starters of PPIs more strictly, that is, receiving a prescription of PPIs at exactly the same date as the first prescription of LDASA. Second, we changed the medical and prescription history into only 1 year before the date of the first LDASA prescription. Third, as LDASA therapy was frequently prescribed for patients with cardiovascular diseases, a separate analysis with solely cardiovascular patients was conducted. Finally, we investigated the influence of irregular users of PPIs into our analysis by performing two analyses in which we (1) merged irregular users with regular users of PPIs and in which we (2) added irregular users to the no PPI users group.

\section{Role of the funding source}

The sponsor had no decisive role in the study, that is, the sponsor thought along with the study and supplied suggestions regarding the content of the study, but the sponsor was not involved in the decisions regarding the analysis, the conduct of the study, nor the publication. JCK and LvD had full access to all data in the study and take responsibility for the integrity of the data and accuracy of the data analysis. All authors had final responsibility for the decision to submit for publication.

\section{RESULTS}

In the study population, 18137 new LDASA users of 18 years and older were identified of whom 12343 were regular users during the years 2008-2010 (figure 1). Of these incident regular LDASA users, 3213 (26\%) were at increased risk for GI complications. The vast majority was at an increased GI risk due to their age. In total, $64.5 \%$ of the patients who were at increased GI risk obtained a PPI prescription; $46.1 \%$ was a regular and $18.4 \%$ an irregular user. In the group of patients with an increased GI risk without PPI prescription, the main reason for having an increased GI risk was age, above 80 years $(n=994,87 \%)$. Cardiovascular diseases are reported in almost half of the patients, and are significantly more prevalent among patients with increased GI risk $(49.3 \%$ vs $46.0 \%, p=0.002)$. The use of comedication is generally higher in the increased GI risk group, with the exception of lipid modifying agents (table 1).

In total, 4204 (34.1\%) patients were regular PPI users, $2456(19.9 \%)$ were irregular users and $5683(46 \%)$ used no PPI (table 2). Of the regular PPI users nearly half of the patients $(48 \%)$ started PPI therapy previously, $25 \%$ started PPI therapy simultaneously and $27 \%$ started subsequently. Patients that started PPI previously, more often were prescribed with drugs for functional GI disorders or acid-related disorders, cardiac therapy, diuretics, $\beta$-blocking agents and vasoprotective agents.

Table 3 shows the probability of receiving regular PPI prescriptions versus no PPI usage. This probability is significantly increased by different risk factors for GI side effects, by morbidity, medication and increased age. LDASA users with a history of GI complications were more likely to receive regular PPI prescriptions (adjusted OR 13.9; $95 \%$ CI 11.8 to 16.4 ), as was found for the 


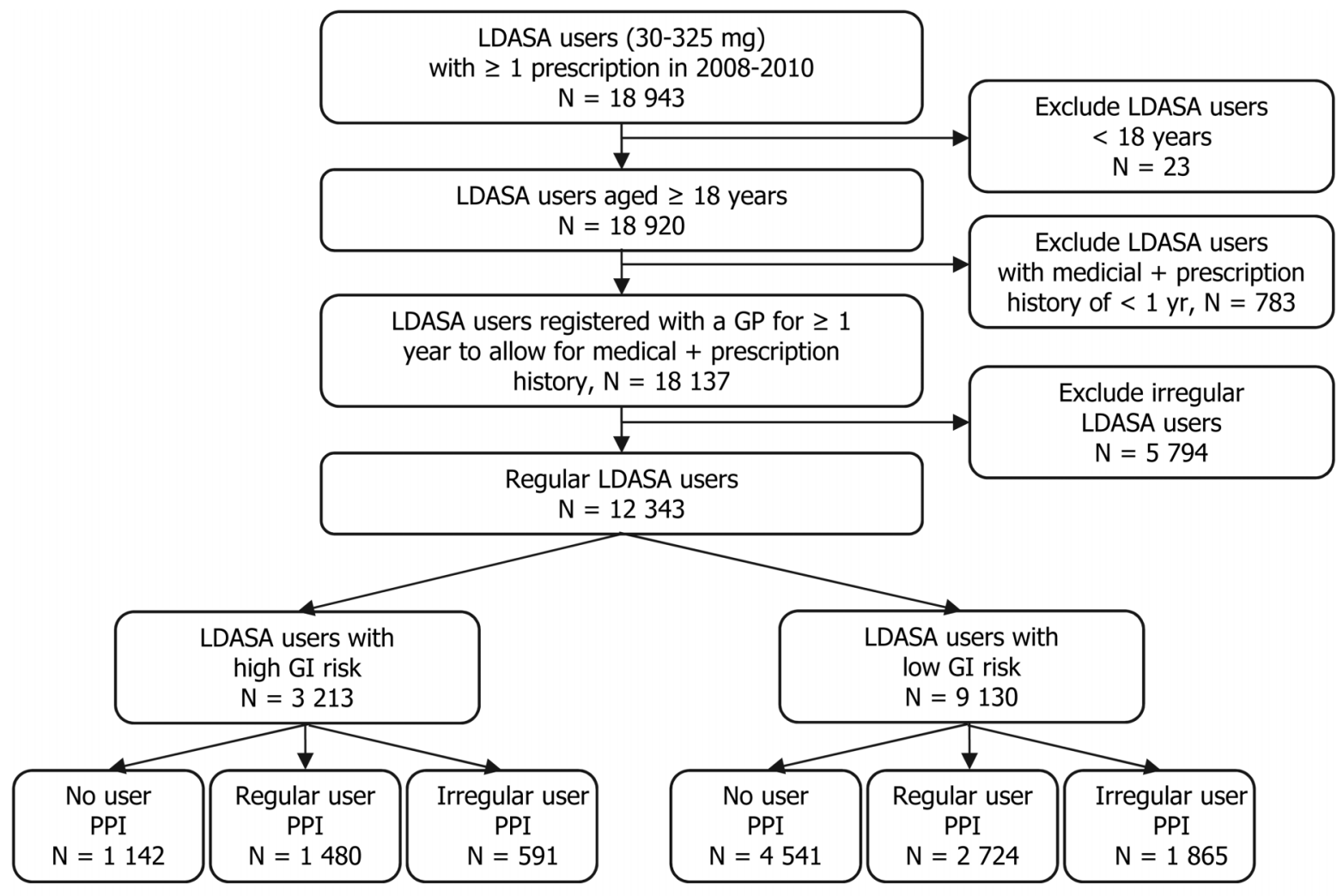

LDASA, low-dose acetylsalicyclic acid; GI, gastrointestinal; PPI, proton-pump inhibitors

Figure 1 Study flow diagram. GI, gastrointestinal; irreg., irregular; LDASA, low-dose acetylsalicyclic acid; PPI, proton-pump inhibitors; reg., regular.

different medications used to define patients with an increased GI risk. Simultaneous use of SSRIs (adjusted OR 9.1 (6.7 to 12.2)), NSAIDs (5.2 (4.3 to 6.3)), glucocorticosteroids (6.1 (4.6 to 8.0)), and being 80 years and older (1.9 (1.5 to 2.3)) were strongly related to receiving a PPI regularly. Sensitivity analyses for the group with an increased GI risk did not alter our findings; similar predicting factors influenced the probability with equal magnitude, except for age. Age was no longer a predicting factor (data not shown).

Applying the different sensitivity analyses did not alter our findings.

\section{DISCUSSION}

We showed that $36 \%$ of the regular LDASA user who have an increased GI risk did not receive prescriptions for PPIs by their primary care physician at all, and another $18 \%$ were irregular PPI users. So, both groups $(54 \%)$ were not treated according to recent recommendations. Several factors increased the probability to obtain PPI prescription regularly; most important factors were previous GI complications, use of SSRIs, NSAIDs, glucocorticosteroids or drugs for functional GI disorders and increased age. The majority of LDASA users started with the PPI treatment before the initiation of LDASA treatment.

A large primary care population-based cohort-study of 50126 NSAID users between 1996 and 2006 showed that physicians are not always aware of the need for gastroprotection when prescribing NSAID. Almost $60 \%$ of new NSAID users with at least one GI risk factor and $52 \%$ of patients with a history of GI bleeding/ulceration were not prescribed any gastroprotective agent. These numbers are almost in the same range as our results; however, this study made no distinction between specific types of NSAIDs. ${ }^{17}$ A Spanish cross-sectional, multicentre study in which 3357 patients from 713 primary care physicians participated, found that $82 \%$ of the NSAID and/ or LDASA users with an increased GI risk received PPIs and $62 \%$ of the low GI risk patients. ${ }^{20}$ So, the vast majority of all NSAID/LDASA users, even the patients with a low risk, received a PPI prescription, which is much higher than observed in our study. Yet, our study has a longitudinal design, and consequently has the information to label a patient as regular or irregular user of PPI. If we drop the strict condition of being a regular PPI user, to mimic a cross-sectional design, $64.5 \%$ of the patients with an increased risk obtained PPIs and 50.2\% of the low risk patients. These numbers are more in line with the Spanish results, although still lower. Next to the 
Table 1 Characteristics of regular low-dose aspirin users with low risk of Gl complications and low-dose aspirin users with an increased risk of GI complications, based on HARM-WRESTLING recommendations

\begin{tabular}{|c|c|c|c|}
\hline & $\begin{array}{l}\text { Patients with increased } \\
\text { risk of Gl complications } \\
\mathrm{N}=3.213\end{array}$ & $\begin{array}{l}\text { Patients with low risk } \\
\text { of } \mathrm{Gl} \text { complications } \\
\mathrm{N}=9.130\end{array}$ & p Value* \\
\hline \multicolumn{4}{|c|}{ Risk factors for GI complications at first prescription of LDASA (\%) } \\
\hline$>80$ years old & $2.543(79.1)$ & NA & NA \\
\hline $\begin{array}{l}>70 \text { years old and simultaneous use of NSAIDs, oral } \\
\text { anticoagulants, glucocorticosteroids, SSRIs and/or } \\
\text { spironolacton }\end{array}$ & $623(19.4)$ & NA & NA \\
\hline$>60$ years old and history of an ulcer & $47(1.5)$ & NA & NA \\
\hline \multicolumn{4}{|l|}{$\operatorname{Sex}(\%)$} \\
\hline Men & $1.283(39.9)$ & $5.352(58.6)$ & $<0.0001$ \\
\hline Age (years) (SD) & $82.6(6.1)$ & $62.1(10.8)$ & $<0.0001$ \\
\hline \multicolumn{4}{|l|}{ LDASA plus PPI use (\%) } \\
\hline No user of PPI & $1.142(35.5)$ & $4.541(49.8)$ & $<0.0001$ \\
\hline Regular user of PPI & $1.480(46.1)$ & $2.724(29.8)$ & \\
\hline Irregular user of PPI & $591(18.4)$ & $1.865(20.4)$ & \\
\hline \multicolumn{4}{|l|}{ Comorbidity (\%)† } \\
\hline \multicolumn{4}{|l|}{ GI tract } \\
\hline Gl complications & $664(20.7)$ & $1.475(16.2)$ & $<0.0001$ \\
\hline Duodenal ulcer & $24(0.8)$ & $21(0.2)$ & $<0.0001$ \\
\hline Peptic ulcer & $34(1.1)$ & $11(0.1)$ & $<0.0001$ \\
\hline Hiatus hernia & $29(0.9)$ & $58(0.6)$ & 0.13 \\
\hline Heart burn & $75(2.3)$ & $233(2.6)$ & 0.52 \\
\hline Haematemesis & $7(0.2)$ & $10(0.1)$ & 0.19 \\
\hline Rectal bleeding & $50(1.6)$ & $97(1.1)$ & 0.04 \\
\hline \multicolumn{4}{|l|}{ Cardiovascular diseases } \\
\hline Cardiovascular diseases $\ddagger$ & $1.584(49.3)$ & $4.196(46.0)$ & 0.002 \\
\hline Acute myocardial infarction & $223(6.9)$ & $792(8.7)$ & 0.003 \\
\hline Heart failure & $432(13.5)$ & $257(2.8)$ & $<0.0001$ \\
\hline Atrial fibrillation & $237(7.4)$ & $509(5.6)$ & 0.0003 \\
\hline Ischaemic heart disease with angina & $476(14.8)$ & $1.328(14.6)$ & 0.72 \\
\hline Ischaemic heart disease without angina & $173(5.4)$ & $638(7.0)$ & 0.003 \\
\hline Atherosclerosis & $176(5.5)$ & $644(7.1)$ & 0.003 \\
\hline Cerebrovascular diseases $\ddagger$ & $756(23.5)$ & $1.480(16.2)$ & $<0.0001$ \\
\hline Stroke & 362 (11.3) & $731(8.0)$ & $<0.0001$ \\
\hline TIA & 326 (10.2) & $541(5.9)$ & $<0.0001$ \\
\hline Hypertension & $1.307(40.7)$ & $3.546(38.8)$ & 0.08 \\
\hline Diabetes mellitus & 779 (24.3) & $1.960(21.5)$ & 0.002 \\
\hline Hypercholesterolaemia & $1.567(48.8)$ & $6.374(69.8)$ & $<0.0001$ \\
\hline \multicolumn{4}{|l|}{ Comedication $(\%) \dagger$} \\
\hline Other drugs for acid-related disorders & $196(6.1)$ & $477(5.2)$ & 0.07 \\
\hline Drugs for functional GI disorders & $277(8.6)$ & $544(6.0)$ & $<0.0001$ \\
\hline Cardiac therapy & $964(30.0)$ & $2.152(23.6)$ & $<0.0001$ \\
\hline Antihypertensive agents & $2.748(85.5)$ & $7.357(80.6)$ & $<0.0001$ \\
\hline Antihypertensives & $55(1.7)$ & $171(1.9)$ & 0.58 \\
\hline Diuretics & $1.594(49.6)$ & $2.456(26.9)$ & $<0.0001$ \\
\hline$\beta$-blocking agents & $1.728(53.8)$ & $5.250(57.5)$ & 0.0005 \\
\hline Calcium channel blockers & $825(25.7)$ & $2.113(23.1)$ & 0.005 \\
\hline RAAS agents & $1.672(52.0)$ & $4.616(50.6)$ & 0.17 \\
\hline Peripheral vasodilators & $4(0.1)$ & $11(0.1)$ & 1.00 \\
\hline Vasoprotectives & $103(3.2)$ & $232(2.5)$ & 0.06 \\
\hline Lipid modifying agents & $1.557(48.5)$ & $6.311(69.1)$ & $<0.0001$ \\
\hline Antidiabetics & $624(19.4)$ & $1.604(17.6)$ & 0.03 \\
\hline
\end{tabular}


Table 2 Characteristics of regular low-dose aspirin users and low-dose aspirin plus irregular and regular proton-pump inhibitors users, stratified by time of proton-pump inhibitor use

\begin{tabular}{|c|c|c|c|c|c|c|}
\hline & \multirow[b]{2}{*}{$\begin{array}{l}\text { No use of } \\
\text { LDASA } \\
\mathrm{N}=5.683\end{array}$} & \multirow[b]{2}{*}{$\begin{array}{l}\text { Irregular use of } \\
\mathrm{PPI} \\
\mathrm{N}=2.456\end{array}$} & \multicolumn{3}{|l|}{$\begin{array}{l}\text { Regular use of PPI } \\
\mathrm{N}=4.204\end{array}$} & \multirow[b]{2}{*}{ p Value* } \\
\hline & & & $\begin{array}{l}\text { Previous starters of } \\
\text { PPI } \\
\mathrm{N}=2.015\end{array}$ & $\begin{array}{l}\text { Simultaneous starters of } \\
\text { PPI } \\
\mathrm{N}=1.064\end{array}$ & $\begin{array}{l}\text { Subsequent starters of } \\
\mathrm{PPI} \\
\mathrm{N}=1.125\end{array}$ & \\
\hline \multicolumn{7}{|l|}{ Age } \\
\hline $18-50$ & 599 (10.5) & $208(8.5)$ & $176(8.7)$ & $58(5.4)$ & $81(7.2)$ & \multirow[t]{4}{*}{$<0.0001$} \\
\hline $51-65$ & $2.026(35.7)$ & $829(33.8)$ & $592(29.4)$ & $292(27.4)$ & $331(29.4)$ & \\
\hline $66-80$ & $2.163(38.1)$ & $1.043(42.5)$ & $801(39.8)$ & 424 (39.9) & $494(43.9)$ & \\
\hline $80+$ & $895(15.8)$ & 376 (15.3) & $446(2.1)$ & $290(27.3)$ & $219(19.5)$ & \\
\hline \multicolumn{7}{|l|}{ Sex } \\
\hline Men & $3.308(58.2)$ & $1.288(52.4)$ & $912(45.3)$ & $530(49.8)$ & $597(53.1)$ & $<0.0001$ \\
\hline \multicolumn{7}{|l|}{ Risk of Gl complications (\%)† } \\
\hline Increased risk of GI complications & $1.142(20.1)$ & $591(24.1)$ & 756 (37.5) & $414(38.9)$ & $310(27.6)$ & \multirow[t]{2}{*}{$<0.0001$} \\
\hline Low risk of Gl complications & $4.541(79.9)$ & 1.865 (75.9) & $1.259(62.5)$ & $650(61.1)$ & $815(72.4)$ & \\
\hline \multicolumn{7}{|l|}{ Comorbidity (\%) $\ddagger$} \\
\hline Gl complications & $214(3.8)$ & $594(24.2)$ & $831(41.2)$ & $217(20.4)$ & $283(25.2)$ & $<0.0001$ \\
\hline Ulcers & $6(0.1)$ & $24(1.0)$ & $38(1.9)$ & $9(0.9)$ & $13(1.2)$ & $<0.0001$ \\
\hline Cardiovascular diseases & 2.447 (43.6) & $1.190(48.5)$ & $1.110(55.1)$ & 456 (42.9) & $547(48.6)$ & $<0.0001$ \\
\hline Cerebrovascular diseases & $1.052(18.5)$ & 400 (16.3) & 406 (20.2) & $171(16.1)$ & $207(18.4)$ & 0.007 \\
\hline Hypertension & $2.221(39.1)$ & $989(40.3)$ & $831(41.2)$ & $335(31.5)$ & $477(42.4)$ & $<0.0001$ \\
\hline Diabetes mellitus & $1.189(20.9)$ & 544 (22.2) & $458(22.7)$ & $292(27.4)$ & $256(22.8)$ & 0.0001 \\
\hline Hypercholesterolaemia & $3.600(63.4)$ & $1.592(64.8)$ & $1.302(64.6)$ & $721(67.8)$ & $726(64.5)$ & 0.09 \\
\hline \multicolumn{7}{|l|}{ Comedication (\%)‡ } \\
\hline $\begin{array}{l}\text { Other drugs for acid-related } \\
\text { disorders }\end{array}$ & $227(4.0)$ & $144(5.9)$ & $163(8.1)$ & $54(5.1)$ & $85(7.6)$ & $<0.0001$ \\
\hline Drugs for functional GI disorders & $151(2.7)$ & $211(8.6)$ & $275(13.7)$ & $83(7.8)$ & $101(9.0)$ & $<0.0001$ \\
\hline Cardiac therapy & $1.142(20.1)$ & $664(27.0)$ & $672(33.4)$ & $324(30.5)$ & $314(27.9)$ & $<0.0001$ \\
\hline Antihypertensive agents & $4.523(79.6)$ & $1.997(81.3)$ & $1.721(85.4)$ & $912(85.7)$ & $952(84.6)$ & $<0.0001$ \\
\hline Antihypertensives & $102(1.8)$ & $36(1.5)$ & $44(2.2)$ & $22(2.1)$ & $22(2.0)$ & 0.48 \\
\hline Diuretics & $1.607(28.3)$ & $782(31.8)$ & $826(41.0)$ & $410(38.5)$ & $425(37.8)$ & $<0.0001$ \\
\hline$\beta$-blocking agents & $3.078(54.2)$ & $1.370(55.8)$ & $1.255(62.3)$ & $633(59.5)$ & $642(57.1)$ & $<0.0001$ \\
\hline Calcium channel blockers & $1.078(21.5)$ & 571 (23.3) & $551(27.3)$ & $286(26.9)$ & $309(27.5)$ & $<0.0001$ \\
\hline RAAS agents & $3.221(49.3)$ & 1.205 (49.6) & $1.081(53.7)$ & $576(54.1)$ & $624(55.5)$ & $<0.0001$ \\
\hline Vasoprotectives & $111(2.0)$ & $77(3.1)$ & $84(4.2)$ & $25(2.4)$ & $38(3.4)$ & $<0.0001$ \\
\hline Lipid modifying agents & $3.568(62.8)$ & 1.578 (64.3) & $1.288(63.9)$ & $717(67.4)$ & $717(63.7)$ & 0.08 \\
\hline Antidiabetics & $974(17.1)$ & $420(17.1)$ & 378 (18.8) & 244 (22.9) & $212(18.8)$ & 0.0001 \\
\hline
\end{tabular}


Table 3 Probability of receiving a proton-pump inhibitor (PPI) regularly versus no PPI in patients treated regularly with low-dose aspirin

\begin{tabular}{|c|c|c|c|}
\hline & \multicolumn{2}{|l|}{$\begin{array}{l}\text { LDASA users } \\
(\mathrm{N}=9.887)\end{array}$} & \multirow[b]{2}{*}{ p Value* } \\
\hline & $\begin{array}{l}\text { Univariate analysis } \\
\text { (OR; 95\% CI) }\end{array}$ & $\begin{array}{l}\text { Multivariate analysis } \\
\text { (OR; } 95 \% \mathrm{Cl})\end{array}$ & \\
\hline \multicolumn{4}{|l|}{ Age (ref=18-50) } \\
\hline $51-65$ & $1.28(1.13$ to 1.46$)$ & $1.09(0.91$ to 1.31$)$ & 0.39 \\
\hline $66-80$ & 1.77 (1.56 to 2.00$)$ & 1.54 (1.28 to 1.84$)$ & $<0.0001$ \\
\hline $80+$ & 2.16 (1.88 to 2.48$)$ & 1.88 (1.54 to 2.30$)$ & $<0.0001$ \\
\hline Gender (ref=male) & 1.48 (1.38 to 1.59$)$ & 1.26 (1.15 to 1.39$)$ & $<0.0001$ \\
\hline Increased risk of $\mathrm{Gl}$ complications (ref=low) $\dagger$ & 2.15 (1.99 to 2.33$)$ & & \\
\hline NSAIDs & 4.05 (3.72 to 4.41$)$ & 5.20 (4.31 to 6.28$)$ & $<0.0001$ \\
\hline Oral anticoagulants & $1.48(1.30$ to 1.68$)$ & $1.46(1.12$ to 1.90$)$ & 0.008 \\
\hline Glucocorticosteroids & 4.39 (3.92 to 4.91$)$ & 6.06 (4.59 to 7.99$)$ & $<0.0001$ \\
\hline SSRIS & 5.88 (4.95 to 6.99$)$ & 9.07 (6.73 to 12.22$)$ & $<0.0001$ \\
\hline Spironolacton & 2.46 (2.04 to 2.96$)$ & 1.64 (1.22 to 2.22$)$ & 0.002 \\
\hline Ulcer & $13.09(6.75$ to 25.40$)$ & & \\
\hline GI complications & $14.88(13.08$ to 16.93$)$ & $13.89(11.78$ to 16.37$)$ & $<0.0001$ \\
\hline Cardiovascular diseases & $1.37(1.27$ to 1.47$)$ & & \\
\hline Cerebrovascular diseases & $0.98(0.89$ to 1.07$)$ & & \\
\hline Hypertension & $1.13(1.05$ to 1.22$)$ & $0.83(0.75$ to 0.92$)$ & 0.001 \\
\hline Diabetes mellitus & 1.21 (1.11 to 1.31$)$ & & \\
\hline Hypercholesterolaemia & 1.19 (1.11 to 1.28$)$ & 1.19 (1.07 to 1.32$)$ & 0.003 \\
\hline Other drugs for acid-related disorders & 1.84 (1.58 to 2.13$)$ & & \\
\hline Drugs for functional GI disorders & 4.62 (3.96 to 5.40$)$ & 2.40 (1.92 to 3.00$)$ & $<0.0001$ \\
\hline Cardiac therapy & 1.85 (1.71 to 2.00$)$ & 1.55 (1.39 to 1.73$)$ & $<0.0001$ \\
\hline Antihypertensive agents & $1.62(1.48$ to 1.77$)$ & $1.34(1.17$ to 1.55$)$ & $<0.0001$ \\
\hline Vasoprotectives & 1.91 (1.55 to 2.33$)$ & $1.42(1.06$ to 1.91$)$ & 0.03 \\
\hline Lipid modifying agents & $1.18(1.10$ to 1.27$)$ & & \\
\hline Antidiabetics & $1.22(1.11$ to 1.33$)$ & $1.11(0.98$ to 1.26$)$ & 0.1 \\
\hline
\end{tabular}

number of increased risk patients receiving PPIs, the timing of the initiation of PPI treatment is important. Our study showed that the vast majority of patients started with PPI treatment before or simultaneously with the first prescription of LDASA, thereby acting as preventive agent.

In line with the HARM-WRESTLING recommendations, the USA, NICE and ESC guidelines also recommend to prescribe PPIs to LDASA users who are 60-70 years of age or older and/or concomitantly use of SSRIs, NSAIDs or glucocorticosteroids. ${ }^{121315}$ Therefore, we believe our findings are not only relevant for the Netherlands but have international implications as well.

The study of Lanas et $a l^{20}$ found that gastroprotective treatment in LDASA users was significantly associated with a prior history of peptic ulcer, high-dose NSAID therapy and concomitant use of oral corticosteroids and antithrombotics. Our data support these findings. In several other population-based studies, having a history of GI complications, including ulcers, is the strongest predictor for receiving a PPI, as is found in our study. 6726
Albeit the number of LDASA users with low GI risk that obtain PPIs is significantly lower compared with the high-risk population, over treatment with PPIs may occur in this group. In total, $30 \%$ of patients with low GI risk received regularly PPI treatment. Although PPI treatment is considered to be cheap, relatively safe, longterm treatment with this drug has been shown to increase the susceptibility to GI infections and pneumonia, and it has been associated with an increased risk of fractures. ${ }^{27-29}$ Unfortunately, the reasons why these low GI risk patients obtained (regular) PPI's by their primary care physician is very incompletely recorded in our database, refraining us to comment on the necessity of these prescriptions in patients with a low GI risk.

The only difference between patients who were at increased GI risk with or without regular PPI therapy was the reason of being a patient with an increased GI risk; nearly $90 \%$ of the patients who were at increased GI risk without regular PPI therapy were above 80 years, whereas of the patients with regular PPI use, just $74 \%$ was above 80 years. Another possible 
explanation why not all patients with an increased GI risk use PPIs regularly might be limited awareness of primary care physicians of the current recommendation, since the draft version was first published in 2008 and the final version in 2009, during the first months of our study period.

A strong point of our study is that we had a large representative sample of patients monitored in daily practice. The vast majority of the primary care centres in the Netherlands have a computerised EMR, allowing us to use routinely recorded medical and prescription data from primary care centres minimising the risk of recall bias. The participating primary care centres are equally distributed throughout the Netherlands and we took possible differences between practices into account by performing multilevel analyses. Another strength is that in our large sample, we had complete data for each individual patient, including all physicians' diagnoses and prescription data. This enabled us to study several different subpopulations of patients combining LDASA and PPI treatment. Finally, we performed a range of sensitivity analyses regarding exposure definition, and inclusion and exclusion criteria.

A limitation of this study includes the lack of information about prescriptions by medical specialists. If PPIs were prescribed by medical specialists, the prescription of the patient might not always appear in our dataset. Yet, the Dutch guidelines for optimising primary caremedical specialist communication support medical specialists to inform primary care physicians with the first results of diagnostics and treatments of the referred patient. $^{30} 31$ Due to this, we may have underestimated regular PPI use. However, it is plausible that LDASA prescription was initiated by the same medical specialist, so if PPI prescriptions are missing, probably LDASA prescriptions are missing as well. In such a case the patient was not included in our study, limiting the impact of missing PPI prescriptions. Our results are based on an observational study which may be subjected to residual confounding due to potential unmeasured differences in GI risk profile and patient characteristics between LDASA users who received or did not receive PPI prescriptions. Finally, we do not have any information why patients with an increased GI risk did not obtain PPI prescriptions, nor do we know the reason why patients become an irregular PPI user, and whether this was patient or physician related.

In conclusion, primary care physicians do not fully adhere to the current recommendations to prescribe PPIs regularly to LDASA users with an increased GI risk. Despite widespread recommendations, more than half of the patients with an increased GI risk are not treated sufficiently with a concomitant PPI, increasing the risk of GI side effects. This finding underlines the necessity to consider merging recommendations in one common, standard and frequently used recommendation by primary care physicians. Further studies are needed to determine which motivations and attitudes may play a role for primary care physicians to be aware of the guidelines and be able to accept, and adhere to them.

Contributors HJldJ contributed to the design of the study, performed data analyses and drafted the report. JCK provided data, contributed to the design of the study and the interpretation of the results and drafted and reviewed the report. LvD initiated and obtained the funding for the project, contributed to the design of the study and interpretation of the results and drafted and reviewed the paper. EV and CEVD performed data analyses, contributed to the interpretation of the data and reviewed the paper. MGHvO contributed to the design of the study and analysis plan, interpretation of the results and reviewed the paper. All authors have read and approved the final manuscript.

Funding The sponsor of the study, AstraZeneca, had no decisive role in design and conduct of the study, collection, analysisor interpretation of the data, or decision to submit the manuscript for publication.

Competing interests The institute of JCK and LVD received research funding from Astra Zeneca and Bristol-Myers Squibb for a study not related to this study. MGHvO has served as a consultant for AstraZeneca and Pfizer, and has received unrestricted research grants from AstraZeneca, Shire and Janssen. JCK and LvD had full access to all data in the study and take responsibility for the integrity of the data and accuracy of the data analysis. All authors had final responsibility for the decision to submit for publication.

Ethics approval The privacy regulation of LINH was approved by the Dutch Data Protection Authority. According to Dutch legislation, neither obtaining informed consent nor approval by a medical ethics committee is obligatory for database studies

Provenance and peer review Not commissioned; externally peer reviewed.

Data sharing statement No additional data are available.

Open Access This is an Open Access article distributed in accordance with the Creative Commons Attribution Non Commercial (CC BY-NC 3.0) license, which permits others to distribute, remix, adapt, build upon this work noncommercially, and license their derivative works on different terms, provided the original work is properly cited and the use is non-commercial. See: http:// creativecommons.org/licenses/by-nc/3.0/

\section{REFERENCES}

1. World Health Organisation. Global atlas on cardiovascular disease prevention and control. 10-1-2012.

2. Antithrombotic Trialists' Collaboration. Collaborative meta-analysis of randomised trials of antiplatelet therapy for prevention of death, myocardial infarction, and stroke in high risk patients. $B M J$ 2002;324:71-86.

3. Baigent $\mathrm{C}$, Blackwell L, Collins R, et al. Aspirin in the primary and secondary prevention of vascular disease: collaborative meta-analysis of individual participant data from randomised trials. Lancet 2009;373:1849-60.

4. Chen ZM, Sandercock P, Pan HC, et al. Indications for early aspirin use in acute ischemic stroke: a combined analysis of 40000 randomized patients from the Chinese acute stroke trial and the international stroke trial. On behalf of the CAST and IST collaborative groups. Stroke 2000;31:1240-9.

5. Wolff T, Miller T, Ko S. Aspirin for the primary prevention of cardiovascular events: an update of the evidence for the U.S Preventive Services Task Force. Ann Intern Med 2009;150:405-10.

6. McQuaid KR, Laine L. Systematic review and meta-analysis of adverse events of low-dose aspirin and clopidogrel in randomized controlled trials. Am J Med 2006;119:624-38.

7. Yeomans ND, Lanas Al, Talley NJ, et al. Prevalence and incidence of gastroduodenal ulcers during treatment with vascular protective doses of aspirin. Aliment Pharmacol Ther 2005;22:795-801.

8. Hsiao FY, Tsai YW, Huang WF, et al. A comparison of aspirin and clopidogrel with or without proton pump inhibitors for the secondary prevention of cardiovascular events in patients at high risk for gastrointestinal bleeding. Clin Ther 2009;31:2038-47.

9. $\mathrm{Ng} \mathrm{FH,} \mathrm{Wong} \mathrm{SY,} \mathrm{Lam} \mathrm{KF,} \mathrm{et} \mathrm{al.} \mathrm{Famotidine} \mathrm{is} \mathrm{inferior} \mathrm{to}$ pantoprazole in preventing recurrence of aspirin-related peptic ulcers or erosions. Gastroenterology 2010;138:82-8.

10. Scheiman JM, Devereaux PJ, Herlitz J, et al. Prevention of peptic ulcers with esomeprazole in patients at risk of ulcer development 
treated with low-dose acetylsalicylic acid: a randomised, controlled trial (OBERON). Heart 2011;97:797-802.

11. Yeomans ND. Reducing the risk of gastroduodenal ulcers with a fixed combination of esomeprazole and low-dose acetyl salicylic acid. Expert Rev Gastroenterol Hepatol 2011;5:447-55.

12. Bhatt DL, Scheiman J, Abraham NS, et al. ACCF/ACG/AHA 2008 expert consensus document on reducing the gastrointestinal risks of antiplatelet therapy and NSAID use: a report of the American College of Cardiology Foundation Task Force on Clinical Expert Consensus Documents. Circulation 2008;118:1894-909.

13. Hamm CW, Bassand JP, Agewall S, et al. ESC Guidelines for the management of acute coronary syndromes in patients presenting without persistent ST-segment elevation: the task force for the management of acute coronary syndromes (ACS) in patients presenting without persistent ST-segment elevation of the European Society of Cardiology (ESC). Eur Heart J 2011;32:2999-3054.

14. Ministerie van Volksgezondheid WeS. Een voorstel van de Expertgroep Medicatieveiligheid met betrekking tot concrete interventies die de extramurale medicatieveiligheid op korte termijn kunnen verbeteren. HARM-WRESTLING. 2009. Den Haag, The Netherlands.

15. NICE. Acute upper gastrointestinal bleedings: management. NICE clinical guideline 141. 2012.

16. Abraham NS, Hlatky MA, Antman EM, et al. ACCF/ACG/AHA 2010 Expert Consensus document on the concomitant use of proton pump inhibitors and thienopyridines: a focused update of the ACCF/ ACG/AHA 2008 Expert Consensus document on reducing the gastrointestinal risks of antiplatelet therapy and NSAID use. A report of the American College of Cardiology Foundation Task Force on Expert Consensus Documents. J Am Coll Cardiol 2010;56:2051-66.

17. Valkhoff VE, van Soest EM, Sturkenboom MC, et al. Time-trends in gastroprotection with nonsteroidal anti-inflammatory drugs (NSAIDs). Aliment Pharmacol Ther 2010;31:1218-28.

18. Hartnell NR, Flanagan PS, Mackinnon NJ, et al. Use of gastrointestinal preventive therapy among elderly persons receiving antiarthritic agents in Nova Scotia, Canada. Am J Geriatr Pharmacother 2004;2:171-80.
19. Sturkenboom MC, Burke TA, Dieleman JP, et al. Underutilization of preventive strategies in patients receiving NSAIDs. Rheumatology (Oxford) 2003;42(Suppl 3):iii23-31.

20. Lanas A, Plazas MA, Gimeno E, et al. Gastroprotection in NSAID and low-dose aspirin users: a cross-sectional study in primary care. Gastroenterol Hepatol 2012;35:1-7.

21. Bianco MA, Rotondano G, Buri L, et al. Gastro-protective strategies in primary care in Italy: the "Gas.Pro." survey. Dig Liver Dis 2010;42:359-64.

22. Stirbu-Wagner I, Dorsman SA, Visscher S, et al. Netherlands Information Network of General Practice (LINH). Utrecht/Nijmegen, NIVEL/IQ, 2012.

23. Schellevis FG, Westert GP, De Bakker DH. [The actual role of general practice in the dutch health-care system. Results of the second dutch national survey of general practice]. Med Klin (Munich) 2005;100:656-61.

24. World Health Organisation. Guidelines for ATC classification and $D D D$ assignment. Oslo: WHO Collaborating Centre for Drug Statistics Methodology-Nordic Council on Medicines, 1999.

25. Lamberts H, Wood M. ICPC. International classification of primary care. Oxford: Oxford University Press, 1987.

26. Derry S, Loke YK. Risk of gastrointestinal haemorrhage with long term use of aspirin: meta-analysis. BMJ 2000;321:1183-7.

27. Leonard J, Marshall JK, Moayyedi P. Systematic review of the risk of enteric infection in patients taking acid suppression. $A m \mathrm{~J}$ Gastroenterol 2007;102:2047-56.

28. Laheij RJ, Sturkenboom MC, Hassing RJ, et al. Risk of community-acquired pneumonia and use of gastric acid-suppressive drugs. JAMA 2004;292:1955-60.

29. Yang YX, Lewis JD, Epstein S, et al. Long-term proton pump inhibitor therapy and risk of hip fracture. JAMA 2006;296:2947-53.

30. Richtlijn overdracht van medicatie gegevens in de keten. 2008. VWS and IGZ.

31. Kvamme OJ, Olesen F, Samuelson M. Improving the interface between primary and secondary care: a statement from the European Working Party on Quality in Family Practice (EQuiP) Qual Health Care 2001;10:33-9. 